\title{
Experimental flood early warning system in parts of Beas Basin using integration of weather forecasting, hydrological and hydrodynamic models
}

\author{
Pankaj R. Dhote ${ }^{1}$, Praveen K. Thakur ${ }^{1}$, S. P. Aggarwal ${ }^{1}$, Vimal C Sharma ${ }^{2}$, Vaibhav Garg ${ }^{1}$, Bhaskar R. Nikam ${ }^{1}$, Arpit Chouksey $1^{1}$ \\ ${ }^{1}$ Indian Institute of Remote Sensing, ISRO, Dehradun, India \\ ${ }^{2}$ Indian Institute of Technology, Hyderabad \\ Email: pdh@iirs.gov.in
}

Commission V, SS: Natural Resources Management

KEY WORDS: flood early warning, WRF, hydrological modelling, hydrodynamic modelling, flood inundation

\begin{abstract}
:
The flood early warning for any country is very important due to possible saving of human life, minimizing economic losses and devising mitigation strategies. The present work highlights the experimental flood early warning study in parts of Beas Basin, India for the monsoon season of 2015. The entire flood early warning was done in three parts. In first part, rainfall forecast for every three days in double nested Weather Research and Forecasting (WRF) domain (9km for outer domain and $3 \mathrm{~km}$ for inner domain) was done for North Western Himalaya NWH using National Centres for Environmental Prediction (NCEP) Global Forecasting System (GFS) 0.25 degree data as initialization state. Rainfall forecast was validated using Indian Meteorological Department (IMD) data, the simulation accuracy of WRF in rainfall prediction above $100 \mathrm{~mm}$ is about $60 \%$. Rainfall induced flood event of August 05-08, 2015 in Sone River (tributary of Beas River) Basin, near Dharampur, Mandi district of Himachal Pradesh caused very high damages. This event was picked three days in advance by WRF model based rainfall forecast. In second part, mean rainfall at sub-basin scale for hydrological model (HEC-HMS) was estimated from forecasted rainfall at every three hours in netcdf format using python script and flood hydrographs were generated. In third part, flood inundation map was generated using Hydrodynamic (HD) model (MIKE 11) with flood hydrographs as boundary condition to see the probable areas of inundation.
\end{abstract}

\section{INTRODUCTION}

Floods are one of the most common and damaging disasters of India. Early warning of floods is most critical for minimizing the losses due to reoccurring floods in many parts of India. North West Himalaya (NWH) is one of the most vulnerable areas in terms of overall natural hazards. The area is susceptible to flash floods, earthquakes, snow avalanches, forest fires, mudflows and landslides. In last few years, numbers of flash floods, cloud burst or extreme rainfall events and floods due to glacier lake outburst have increased in frequency. The flash floods of Leh-2010 (Kumar et al., 2012; Thayyen et al., 2013), Uttarkashi floods-2012 (Gupta et al., 2013), Manali cloud burst induced flash flood-1995 and 2012 (Thakur et al., 2010), Ukhimath floods 2012 (Rana et al., 2012; DMMC, 2012), Uttarakhand floods-2013 (Dobhal et al., 2013), Kedarnath floods and GLOF 2013 (Dobhal et al., 2013; Rao et al., 2013; Kumar et al., 2015), Sirmor, Himachal Pradesh flash floods2014, Srinagar, Kashmir flood -2014 (Bhatt et al., 2016) are few of examples of recent flood disasters in NWH states of India. Traditionally, remote sensing has been used on regular and operational basis for many applications of hydrology and water resources management (Bhavsar, 1984; Rao et al, 2013). In case of floods, frequently used data during and post flood time is Synthetic Aperture Radar (SAR) and cloud free optical datasets (Rao et al., 2011; Aggarwal et al. 2009) for flood inundation mapping and flood models calibration/validation activities (Rao et al., 2013). Use of remote sensing data before and after flood event is mainly done in creating updated base maps having geo-located layers of elevation, infrastructure and Land Use Land Cover (LULC). In addition to this, time series of historical flood inundation maps are used to create flood hazards maps at various scales.

Flood early warning activities are mainly part of pre-flood management plans. The flood early warning is now becoming one of most important task of many disaster support and management agencies, academia and space agencies globally. Many countries, disaster management agencies and river basins authorities have initiated and setup the flood early warning centres systems (Jorgensen et al. 1997; Thielen et al. 2009; Navalgund, 2014). National Water Model (NWM) framework have been made operational across US in 2016 to translate streamflow forecast into flood inundations maps (http://water.noaa.gov/about/nwm). In India, near real time streamflow forecast system has been developed for BhakraBeas Basin and Bhima Basin under Hydrology Project II (RTDSS 2015). Results of the developed systems depends on the accuracy of near real time meteorological data used in hydrological models. Despite new inventions, converting generated hydrographs into time varying flood inundations maps with speed and reasonable accuracy is a challenge.

In all the flood early warning studies, accurate prediction of rainfall remains most important task (Mukhopadhyay, 2015), other important factors are parameterization of hydrological models, accuracy and resolution of Digital Elevation Models (DEM) (Alemseged and Rientjes, 2005), scale and details of LULC and soil map. Rainfall events have increased in there frequency as well in their intensity. In this study attempt has been made to establish flood early warning system using integration of weather forecasting, hydrological and hydrodynamic models.

\section{MATERIALS AND METHODS}

Study area of this work is Sone River Basin, Himachal Pradesh (HP), India as shown in Figure 1. Sone River is a tributary of Beas River having catchment area of $230 \mathrm{~km}^{2}$ with outlet at Kandhapatan, Mandi district, HP. It is the region where the 
hydrology dominates due to high rainfall and faces high flood situation in every monsoon.

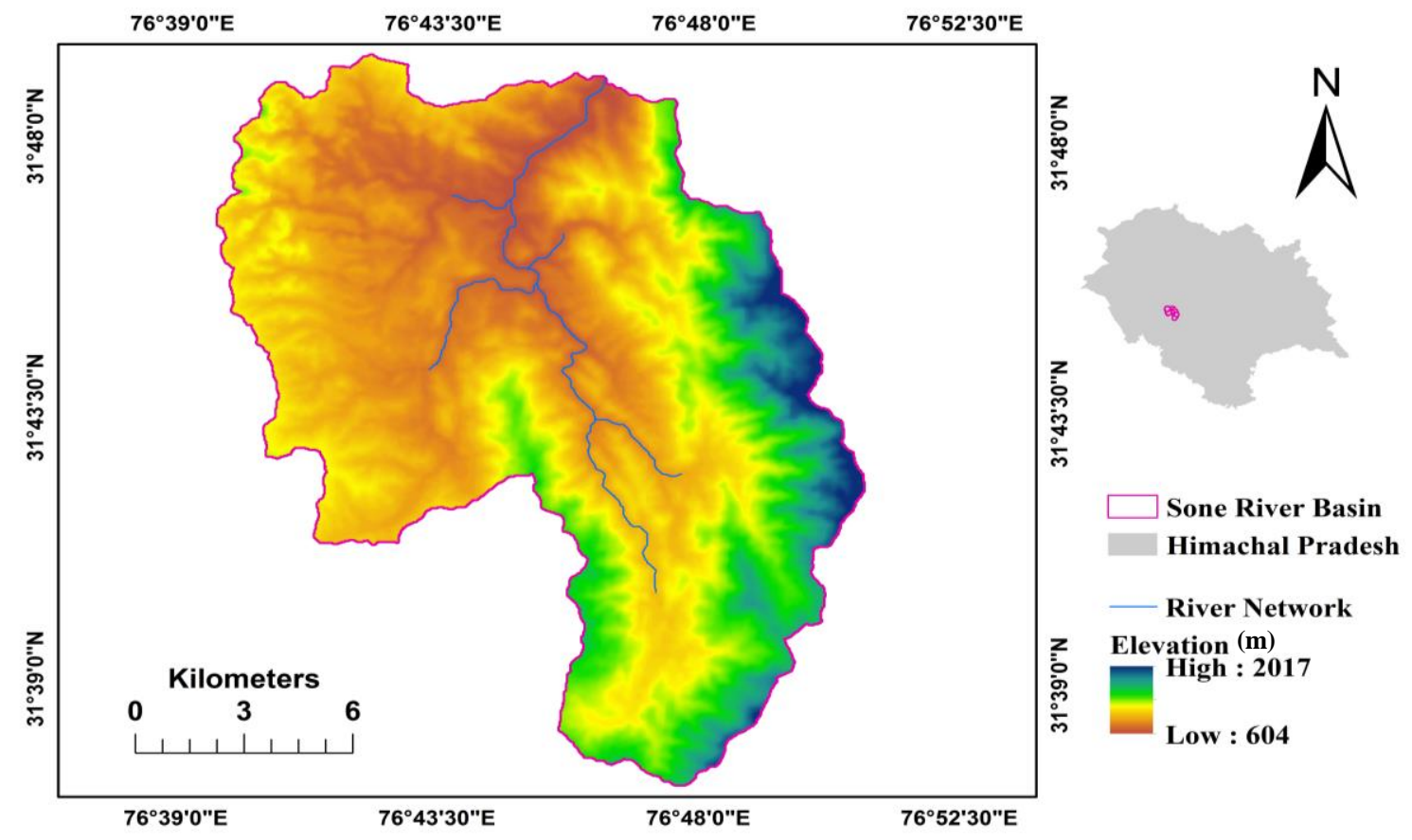

Figure 1. Study Area: Sone River Basin and River Network

The overall methodology adopted in the study is show in Figure 2. The flood early warning system is divide into the three parts. In first part, precipitation forecast for every three days in double nested WRF domain (9km for outer domain and $3 \mathrm{~km}$ for inner domain, as shown in Figure 3) was done for NWH using NCEP GFS 0.25 degree data as initialization state. The listing of physics options used in WRF for weather forecast are given in Table 1. In second part, the forecasted precipitation of selected hours in netcdf format was used in python based codes to get zonal statistics of mean rainfall at sub-basin scale. NCEP's GFS downscaled rainfall data at $3 \mathrm{~km}$ from WRF simulation, IMD (Indian Meteorological Department) grid of $50 \mathrm{~km}$ resolution, INSAT 3D IMR data at 0.5 degree and CPC daily rainfall inputs were the different rainfall datasets analysed for hydrological modelling. Out of all the mentioned datasets, only WRF's 3-day forecasted rainfall and IMD's district wise five day ensemble forecast were used for flood hydrograph predation using HECHMS model (HEC, 2000). ASTER GDEM of 30m resolution was used for the delineation of the catchments and rivers. Hydrological model was established using SCS method for initial loss estimation, SCS unit hydrograph as runoff transformation, Muskingum-Cunge method as channel routing and constant base flow. In third part, flood inundation scenarios were generated using MIKE 11 based HD modelling (DHI, 2014). Cross-sections were generated using SRTM-X band 30m DEM and roughness coefficients were estimated based on ISRO-IGBP LULC map (NRSC, 2008: Indian Space Research Organisation-International Geosphere Biosphere Programme, Land use land cover). Hydrographs generated using hydrological modelling were used as boundary conditions in MIKE $11 \mathrm{HD}$ modelling to see the probable areas in the vicinity of the river which may inundate.

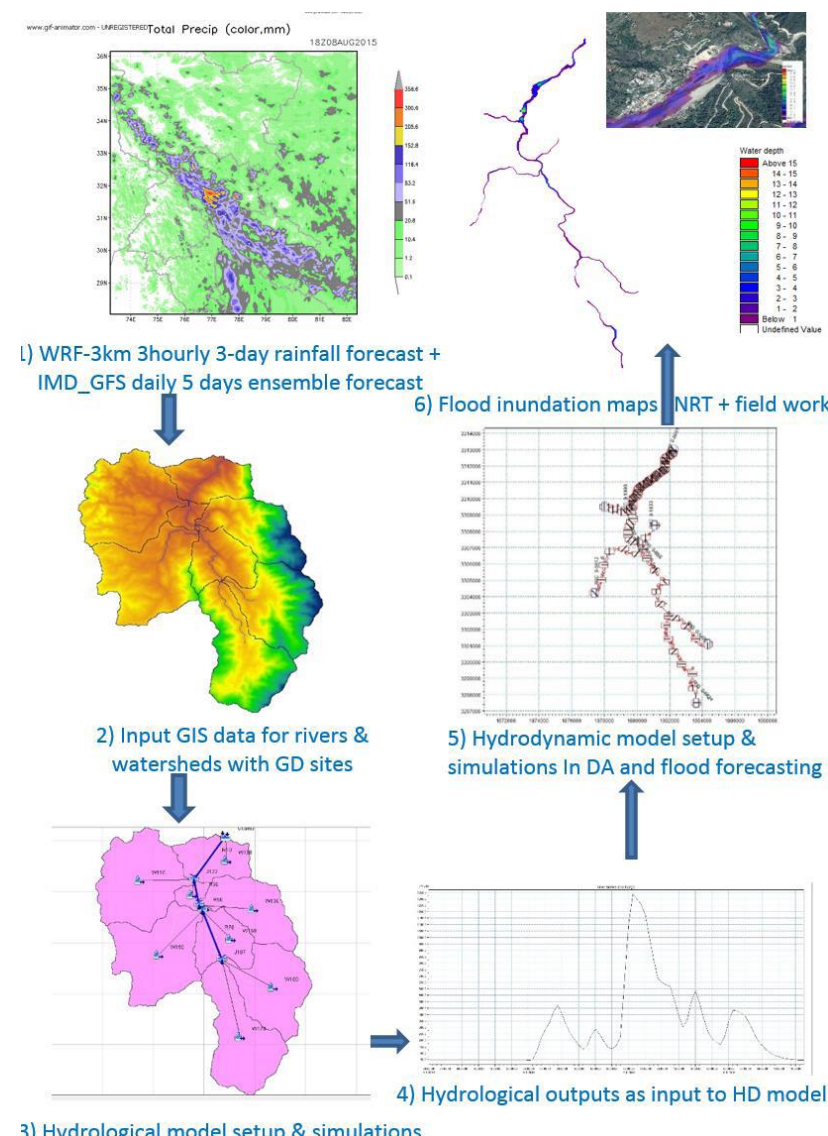

Figure 2. Overall methodology pictorial flowchart 


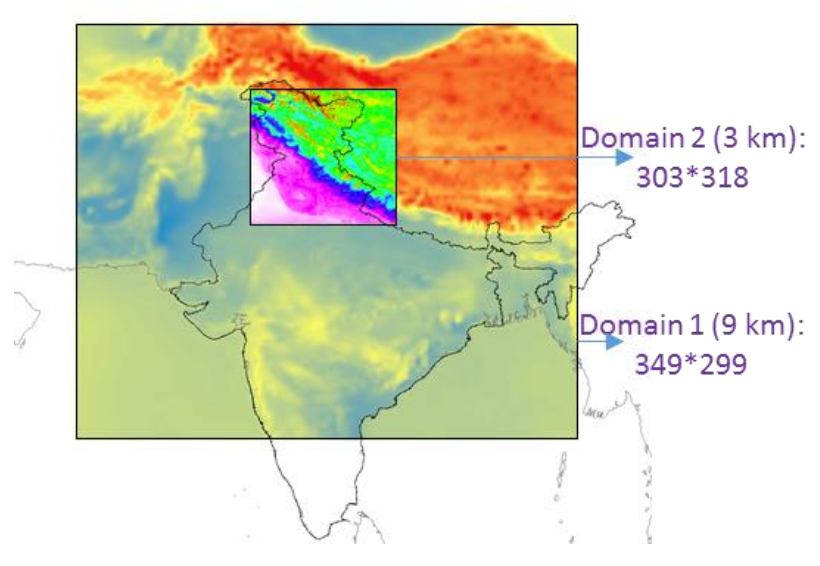

Figure 3: Domains for WRF simulations

Table 1: WRF physics schemes used for simulations

\begin{tabular}{|l|l|l|}
\hline Code & Physics Option & Used scheme/algorithm \\
\hline 6 & $\begin{array}{l}\text { Microphysics } \\
\text { (mp_physics) }\end{array}$ & $\begin{array}{l}\text { WRF Single-Moment 6-class scheme: A scheme with ice, } \\
\text { snow and graupel processes suitable for high-resolution } \\
\text { simulations }\end{array}$ \\
\hline 1 & $\begin{array}{l}\text { Longwave Radiation } \\
\text { ra_lw_physics }\end{array}$ & $\begin{array}{l}\text { RRTM scheme: Rapid Radiative Transfer Model. An accurate } \\
\text { scheme using lookup tables for efficiency. Accounts for } \\
\text { multiple bands, trace gases, \& microphysics Species }\end{array}$ \\
\hline 1 & $\begin{array}{l}\text { Shortwave Radiation } \\
\text { (ra_sw_physics) }\end{array}$ & $\begin{array}{l}\text { Dudhia scheme: Simple downward integration allowing } \\
\text { efficiently for clouds and clear-sky absorption and scattering }\end{array}$ \\
\hline 2 & $\begin{array}{l}\text { Land Surface } \\
\text { (sf_surface_physics) }\end{array}$ & $\begin{array}{l}\text { Noah Land Surface Model: Unified NCEP/NCAR/AFWA } \\
\text { scheme with soil temperature and moisture in four layers, } \\
\text { fractional snow cover and frozen soil physics. }\end{array}$ \\
\hline 2 & $\begin{array}{l}\text { Cumulus } \\
\text { Parameterization } \\
\text { (cu_physics) }\end{array}$ & $\begin{array}{l}\text { Betts-Miller-Janjic scheme, Operational Eta scheme. Column } \\
\text { moist adjustment scheme relaxing towards a well-mixed } \\
\text { profile }\end{array}$ \\
\hline
\end{tabular}

\subsection{RESULTS AND DISCUSSION}

The first output of given methodology for flood early warning is WRF-ARW model based rainfall forecast. Rainfall forecast was done for entire monsoon in 2015 at every three days. An example of very heavy rainfall (Aug 05-08, 2018) in Mandi district, HP forecasted in three days advance is shown in Figure 4. WRF based rainfall forecast was validated with IMD 0.5 degree daily data as reference and using the Model Evaluation Tools (MET) model (Brown et al., 2009). Figure 5 shows results of validation, WRF model was able to pick most of the rainfall events above $100 \mathrm{~mm}$ (accuracy > 60\%) but pixel to pixel correlation between forecasted rain and IMD grid was very poor, with $\mathrm{R}^{2}$ (coefficient of determination) less than 0.3 .

Heavy rainfall during Aug 05-08, 2015 resulted in flood disaster at Sone River Basin near Dharampur, HP. This event was used to highlight the overall approach of flood early warning system. Hydrograph generated using HEC-HMS for the mentioned heavy rainfall event at outlet is shown in Figure 6a. Dynamic flood inundation maps were generated using MIKE 11 with boundary conditions based on hydrological model hydrographs, maximum flood extent is shown in Figure $6 \mathrm{~b}$. The flood inundation map generated from HD model has correctly shown flood inundation in most of parts. However, data gaps were seen in main river channel and points of river curvature (Figures $6 \mathrm{c} \& \mathrm{~d}$ ).
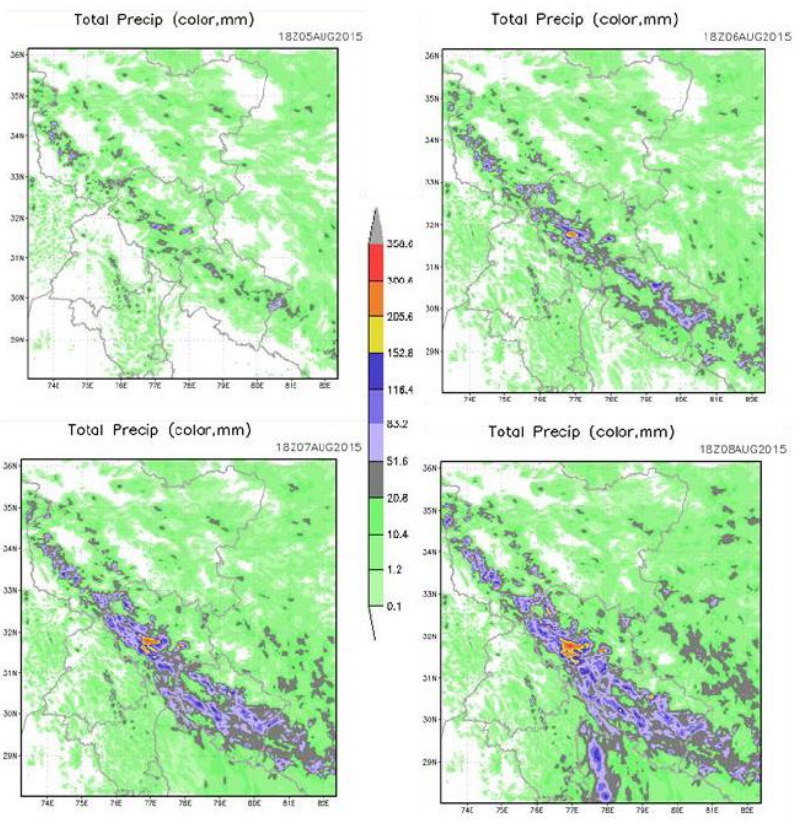

Figure 4. Forecasted rainfall on dated Aug 05, 2015 for Aug 0508, 2018, showing very heavy rainfall in Mandi district, HP

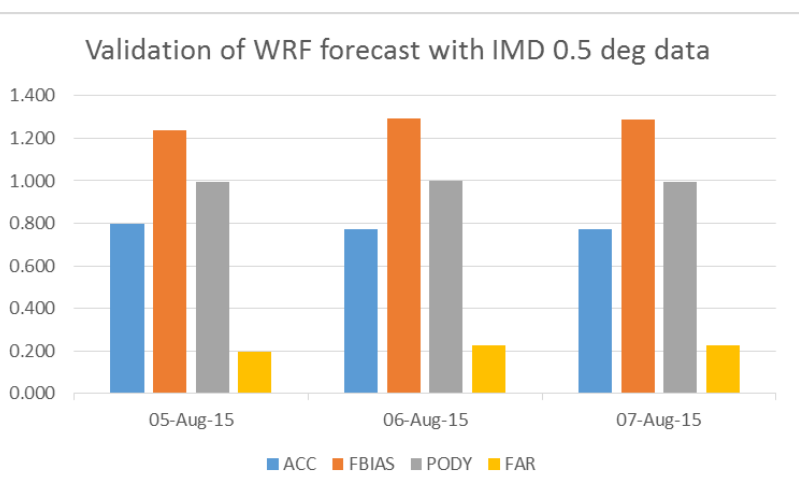

Figure 5. Rainfall prediction above $100 \mathrm{~mm}$ statistical outputs form MET tool (ACC: accuracy; FBIAS: frequency of bias; PODY: probability of detection; FAR: False Alarm Ratio)

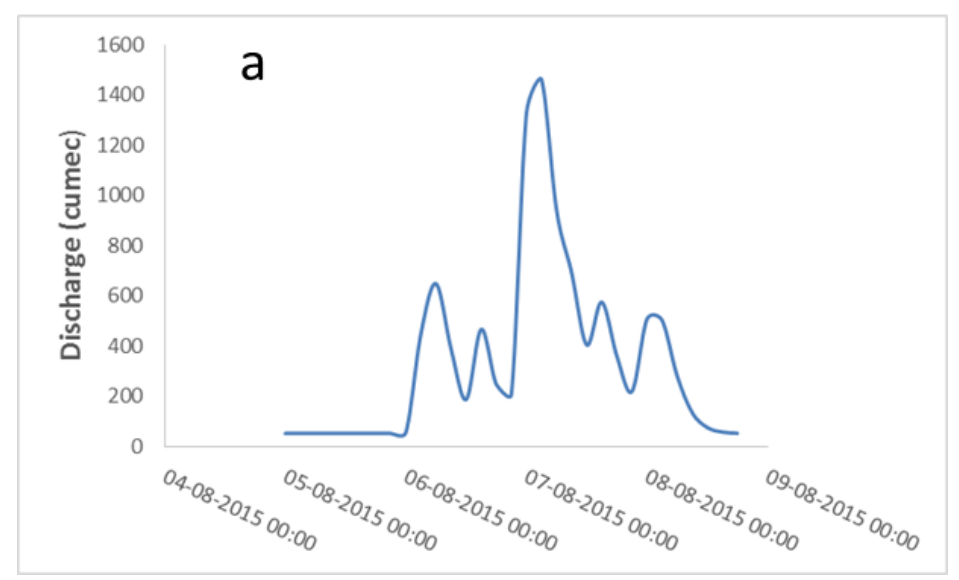



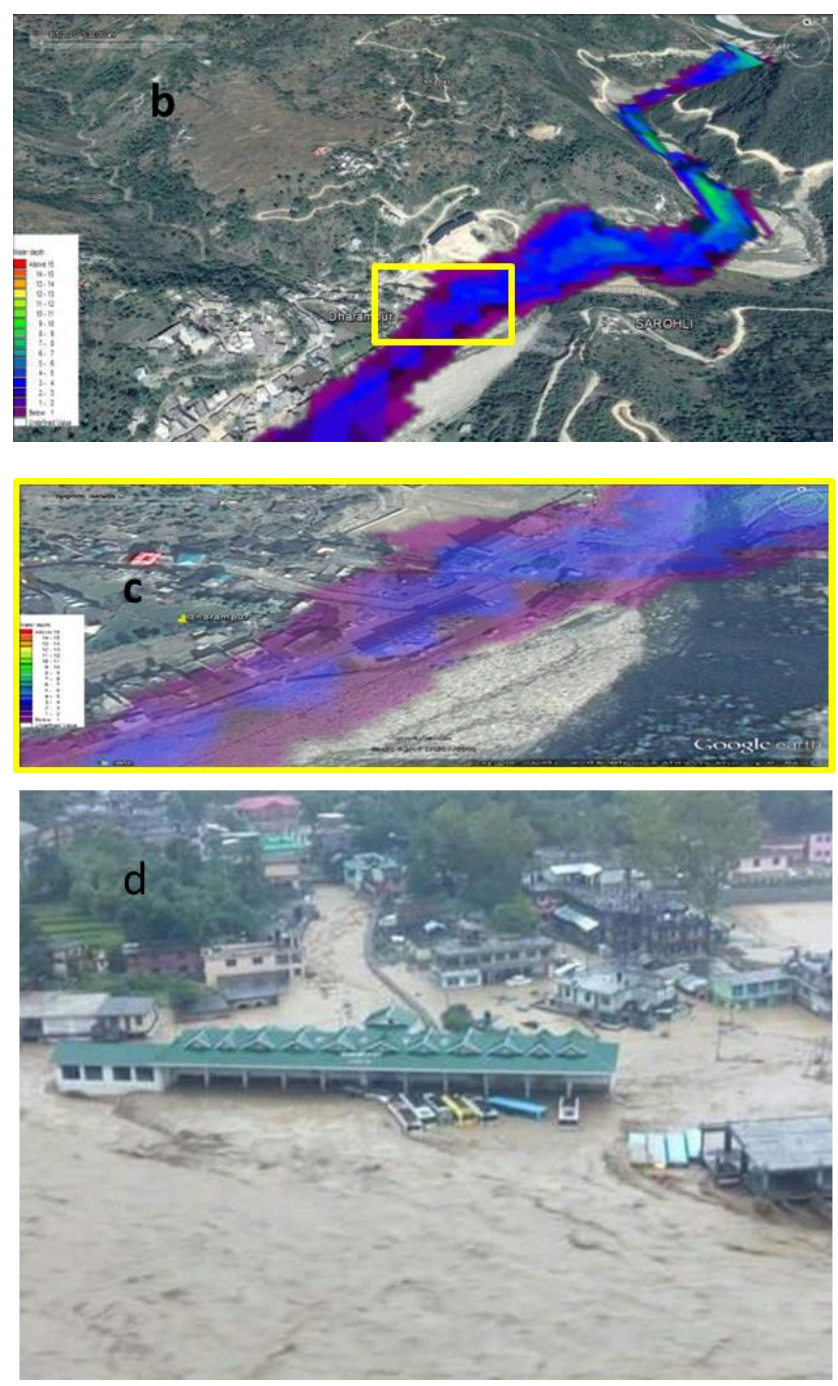

Figure 6. Results of heavy rainfall events and subsequent simulated and actual floods in Dharampur, Mandi, H.P. a) Flood hydrograph using HEC-HMS b) Simulated flood inundation using MIKE 11 c \& d) Simulated and actual flood inundation situation near Bus stand, Dharampur, Mandi district.

\section{CONCLUSIONS AND LIMITATIONS}

The current work highlights the flood early warning system using integration of weather forecast, hydrological and hydrodynamic models for complex terrain of NWH. Forecasted rainfall ensemble with IMD data was used for hydrographs generation using hydrological modelling. HD model was established to simulated flood inundation using produced hydrographs as boundary condition. Based on visual inspection there was good agreement between simulated and actual flood extent near Dharampur, HP. However, there are certain limitations of the study as explained below.

The study showed that, although overall accuracy of weather forecast model, WRF-ARW in this case is able to correctly pick the high rainfall events having more than $100 \mathrm{~mm}$ rainfall at medium time range of 3 days, but comparison with IMD rainfall data product showed a poor pixel to pixel correlation as well as time lag of few hours in picking heavy rainfall. The WRF rainfall forecast can improved by running simulations at daily interval instead of once in every three days. The current study was done without calibration and validation of hydrological/hydrodynamic models due non availability of gauging data for Sone River. Results can improved using stable models (calibrated and validated). The accuracy of flood inundation map is highly dependent on flow hydrographs as well as input DEM. The actual river cross section data is also needed to improve results of flow routing and flood inundation.

\section{ACKNOWLEDGEMENTS}

Authors would like to thank the director, IIRS for all the initiatives, support, suggestions and encouragement for completion of this work. Our appreciation also goes to NCAR, NCEP-GFS, IMD and USGS for providing meteorological and topographical inputs required in the study. This work is done under ISRO-DMS (R\&D) funded project on "Remote sensing, ground observations and integrated modelling based early warning system for climatic extremes of North West Himalayan region".

\section{REFERENCES}

Aggarwal, S.P., P.K. Thakur and V.K. Dadhwal (2009). Remote sensing and GIS applications in flood management. Journal of Hydrological Research and Development, Theme Flood Management, 24, pp.145-158.

Alemseged, T.H., and Rientjes, T.H.M. (2005). Effects of LIDAR DEM resolution in flood modelling: a model sensitivity study for the city of Tegucigalpa, Honduras. ISPRS WG III/3, III/4, V/3 Workshop "Laser scanning 2005", Enschede, the Netherlands.

Bhavsar, P. (1984), Review of remote sensing applications in hydrology and water resources management in India, $A d v$. Space Res., 4, pp. 193-200.

Brown, B. G., J. H. Gotway, R. Bullock, E. Gilleland, T. Fowler, D. Ahijevych, and T. Jensen (2009), The Model Evaluation Tools (MET): Community tools for forecast evaluation, paper presented at Preprints, 25th Conference on International Interactive Information and Processing Systems (IIPS) for Meteorology, Oceanography, and Hydrology, Phoenix, AZ, Amer. Meteor. Soc. A., American Meteorological Society, Boston, Mass.

DHI (2014). MIKE 11, A Modeling System for Rivers and Channels, User Guide. Danish Hydraulic Institute, Horsholm, Denmark.

DMMC, (2012). Investigation in the Asia Ganga valley on the aftermath of flashflood/ landslide of incidences in August, 2012 - A report. Disaster Mitigation and Management Centre (DMMC), Uttarakhand Secretariat, Dehradun.

Dobhal D. P., Gupta, A.K., Mehta, M. and Khandelwal, D.D. (2013). Kedarnath disaster: facts and plausible causes, Current Science, 105(2), pp. 171-174.

Gupta, V., Dobhal, D.P. and Vaideswaran, S. C. (2013). August 2012 cloudburst and subsequent flash flood in the Asi Ganga, a 
tributary of the Bhagirathi river, Garhwal Himalaya, India, Current science, 105(2), 249-253.

HEC (2000), U.S. Army Corps of Engineers-Hydrological Modelling System HEC-HMS, Technical Reference Manual. Davis, CA: U.S. Army Corps of Engineers, Hydrologic Engineering Centre.

Jorgensen, G. H., and J. Host-Madsen. (1997). Development of a Flood Forecasting System in Bangladesh. In Proceedings of Conference on Operational Water Management, pp. 137-148. 3-6 September 1997, Copenhagen. AA Balkema.

Kumar, M.S. Shekhar, M.S. Rama Krishna, S.S.V.S. Bhutiyani, M.R. and Ganju, A. (2012). Numerical simulation of cloud burst event on August 05 2010, over Leh using WRF mesoscale model. Nat. Hazards, doi: 10.1007/s11069-012-0145-1.

Kumar, P., Shukla, B.P., Sharma, S., Kishtawal, C.M. and Pal, P.K. (2015).A high-resolution simulation of catastrophic rainfall over Uttarakhand, India. Nat Hazards, pp. 1-16, DOI 10.1007/s11069-015-2013-2.

Mukhopadhyay, B. (2015). The pattern of Heavy Rainfall events over India. WMO 3rd International Monsoon Heavy Rainfall Workshop, India Meteorological Department during 22- 24 September 2015, New Delhi, India page 14.

Navalgund, R. (2014). Need for developing effective early warning systems for natural disasters using space technology. Guest Editorial in Current Science, 107(6), 935-936.

NRSC, 2008. National Land Use and Land Cover Mapping using AWiFS Data, Report. Hyderabad, India.

Rana, N., Sundriyal, Y. P. and Juyal, N. (2012). Recent cloud burst-induced landslides around Okhimath, Uttarakhand. Curr. Sci., 2012, 103, 1389-1390.

Rao, D. K. H. V., Rao, V.V., Dadhwal, V.K. and Diwakar, P.G. (2013). Kedarnath flash floods: a hydrological and hydraulic simulation study. Current Science, 106(4), 598-603.

Rao, D. K.H.V., Rao, V. V., Dadhwal, V. K., Behera G. and Sharma, J. R. (2011). A Distributed Model for Real-Time Flood Forecasting in the Godavari Basin Using Space Inputs. Int. J. Disaster Risk Sci. 2011, 2 (3): pp. 31-40.

Thakur, P.K., Maity, D., Parodi, G., Aggarwal, S.P. and Nikam, B.R. (2010). Hydrological and 1-d hydrodynamic modeling in Manali sub-basin of Beas river, Himachal Pradesh, India. 3rd International ASCE-EWRI international conference on Perspective on Current \& Future State of Water Resources \& the Environment, January 5-7, 2010, Chennai, India.

Thayyen, R.J., A. P. Dimri, P. Kumar and G. Agnihotri (2013). Study of cloudburst and flash floods around Leh, India, during August 4-6, 2010, Nat Hazards, 65,pp-2175-2204

Thielen, J., J. Bartholmes, M.-H. Ramos, and A. de Roo. (2009). The European Flood Alert System-Part 1: Concept and Development. Hydrology and Earth System Sciences 13 (2), pp. $125-40$. 